\title{
Release of trace metals during wildfires
}

\author{
CYNTHIA F ISLEY ${ }^{1}$, MARK P TAYLOR ${ }^{1}$
}

${ }^{1}$ Macquarie University, NSW Australia, cynthia.isley@mq.edu.au, mark.taylor@mq.edu.au

Wildfires are a natural part of the environment and release fine particles into the atmosphere, including toxic organic and inorganic pollutants previously emitted into the environment and stored within the vegetation biomass and in adjacent soils. Despite extensive research on the adverse impacts of wildfire smoke (particulates and organic compounds) on human health, there is relatively little on the composition and concentration of trace metal contaminants released during fires. This issue is particularly relevant in the current environment of a warming climate, drier and longer summer seasons and more intense fires, as experienced on both sides of the Pacific basin in the last few years.

To address the knowledge gap around trace metal release during wildfires, this study examines whether wildfire activity increases the concentration of atmospheric trace metal contaminants. This study examines trace element concentrations in air before, during and after four major fire events surrounding Australia's largest city of Sydney. Filters $(\mathrm{n}=87)$ were analysed for $\mathrm{Al}, \mathrm{As}, \mathrm{Cd}, \mathrm{Ca}, \mathrm{Co}, \mathrm{Fe}, \mathrm{Pb}, \mathrm{Mn}, \mathrm{Ni}$, $\mathrm{K}, \mathrm{Si}, \mathrm{Ti}$ and $\mathrm{Zn}$ from four Sydney air sampling locations. Mood's median test was used to determine whether significant difference existed for trace element concentrations during fire periods.

Concentrations in air of $\mathrm{Mn}, \mathrm{Ni}, \mathrm{K}$ and $\mathrm{Si}$ were significantly higher during fire periods than before and/or after fire periods. Other elements did not show significant difference during fire periods. Relative mass contribution from different elements or their concentration relative to $\mathrm{Si}$ (as a soil proxy) did not vary significantly during fire periods.

PMF modelling is particualry useful in separting source contributions when individual elements arise from multiple sources. Two distinct factors were identified from the PMF modelling: one factor related to soil components $(\mathrm{Ca}, \mathrm{Si}, \mathrm{Ti}$ and $\mathrm{Zn}$ ) and the other to anthropogenically-sourced toxic metal contaminants $\mathrm{Cd}$ and $\mathrm{Pb}$. The anthropogenic factor was present in significantly higher concentrations during fire periods. This indicates that wildfires relate to an increase of anthropogenic trace metal contaminants such as $\mathrm{Cd}$ and $\mathrm{Pb}$ in the atmosphere.

Further data, particularly that collected during wildfire events, will allow refinement of the model and more accurate characterisation of wildfire emissions. 